\title{
Assessment of daily activity patterns and biomarkers of pain, inflammation, and stress in lactating dairy cows diagnosed with clinical metritis
}

\author{
A. A. Barragan, ${ }^{*}$ J. M. Piñeiro, ${ }^{*}$ G. M. Schuenemann, ${ }^{*}$ P. J. Rajala-Schultz,† D. E. Sanders,ł J. Lakritz,§ \\ and S. Bas*1 \\ *Department of Veterinary Preventive Medicine, College of Veterinary Medicine, The Ohio State University, Columbus 43210 \\ †Department of Production Animal Medicine, University of Helsinki, Paroninkuja 20, 04920 Saarentaus, Finland \\ ‡Vaca Resources, Urbana, OH 43078 \\ §Department of Veterinary Clinical Sciences, The Ohio State University, Columbus 43210
}

\begin{abstract}
The objectives of the present case-control study were to assess (1) daily activity patterns (lying time, number of steps, number of lying bouts, and lying bout duration), and (2) circulating concentrations of biomarkers of pain (substance P), inflammation (haptoglobin), and stress (cortisol) in lactating dairy cows diagnosed with clinical metritis. Lactating dairy cows $(\mathrm{n}=200)$ from 2 commercial dairy herds were enrolled in the present study. Cows diagnosed with clinical metritis $(\mathrm{n}=100)$ at $7 \pm 3 \mathrm{~d}$ in milk were matched according to lactation and days in milk to cows without clinical metritis (NO$\mathrm{CM} ; \mathrm{n}=100)$. On study d 1 , clinical metritis was diagnosed (using a Metricheck device, Simcro Tech Ltd., Hamilton, New Zealand) by the presence of watery, reddish, or brownish foul-smelling vaginal discharge, and blood samples were collected for assessment of circulating concentration of substance $\mathrm{P}$, haptoglobin, cortisol, total calcium, $\beta$-hydroxybutyrate, and blood cells. In addition, on study d 1 body condition of cows was visually assessed, and activity monitors were placed on the hind leg of a subset of cows (CM, n $=56$; CON, $\mathrm{n}=56$ ) and were kept until study $d 7$. Cows showing any other signs of other diseases were not included in the study. Cows with clinical metritis tended to spend more time lying $(\mathrm{CM}=628.92 \mathrm{~min} / \mathrm{d}$; NO-CM $=591.23 \mathrm{~min} / \mathrm{d})$ compared with NO-CM cows. Activity analysis by parity revealed that primiparous cows with clinical metritis spent more time lying compared with primiparous cows without clinical metritis. However, no differences in daily lying time were observed between multiparous cows with and without clinical metritis. Furthermore, cows in the CM group had a higher circulating concentration of substance $\mathrm{P}(\mathrm{CM}=47.15 \mathrm{pg} / \mathrm{mL}$; NO-CM $=37.73 \mathrm{pg} / \mathrm{mL})$ and haptoglobin $(\mathrm{CM}=233.00 \mu \mathrm{g} /$
\end{abstract}

Received January 29, 2018.

Accepted May 13, 2018.

${ }^{1}$ Corresponding author: s.bas@phytobiotics.com
$\mathrm{mL} ;$ NO-CM $=99.98 \mu \mathrm{g} / \mathrm{mL}$ ) when compared with NO-CM cows. Cows with clinical metritis had lower body condition score, and a greater proportion of cows in this group had hypocalcemia when compared with cows without clinical metritis. The circulating concentration of leukocytes and erythrocytes were decreased in cows with clinical metritis compared with cows without clinical metritis. Results from this study showed that concentrations of markers of inflammation, stress, pain, and activity were affected in cows diagnosed with clinical metritis; thus, strategies aimed to minimize the negative effects associated with clinical metritis may be required to improve the welfare of dairy cows.

Key words: dairy cattle, substance P, haptoglobin

\section{INTRODUCTION}

Clinical metritis is an inflammatory process that affects all layers of the uterus during the early postpartum period in lactating dairy cows (Bondurant, 1999; Sheldon et al., 2006). This condition is characterized by the presence of an abnormally enlarged uterus with fetid red-brownish uterine discharge, with or without systemic signs of illness such as depression, anorexia, decreased milk yield, and pyrexia within $21 \mathrm{~d}$ after parturition (Sheldon et al., 2006). The incidence of clinical metritis ranges from 15 to $20 \%$, although it could be higher depending on the herd (Gilbert, 2016). Clinical metritis negatively affects profitability due to reduced milk yield (Rajala and Gröhn, 1998), delayed time to conception (Fourichon et al., 2000), and increased culling rates (Gröhn et al., 2003). Furthermore, a recent study reported that cows with clinical metritis experienced visceral pain in response to palpation of the uterus (Stojkov et al., 2015). Thus, in addition to the negative economic implications, clinical metritis could be regarded as a welfare concern.

Early identification, examination, and treatment of sick animals are crucial to ensure animal welfare in food animal production systems. However, animals such as 
cattle are stoic and physical and behavioral changes associated with diseases and pain can be subtle, making their identification challenging (Fitzpatrick, 2002). Activity monitors have been used to assess the effects of common health events on dairy cattle behavior. Huzzey et al. (2007) showed that prepartum DMI and feeding behavior were altered in cows that developed clinical metritis after calving. Liboreiro et al. (2015) reported that cows diagnosed with clinical metritis spent less time ruminating and had reduced activity compared with cows without clinical metritis. More recently, Stangaferro et al. (2016a,b) showed that the combination of rumination and activity accurately identified cows at the onset of diseases such as displaced abomasum and ketosis; however, it lacked sensitivity to identify cows with clinical metritis. Therefore, the association of clinical metritis and activity patterns in dairy cows warrants further research.

Biomarkers of inflammation and stress such as haptoglobin (HP) and cortisol have been used to assess inflammation and stress in dairy cows with clinical metritis and other postpartum diseases (Huzzey et al., 2009, 2011; Burnett et al., 2015). More recently, substance P (SP) has emerged as a potential marker of nociception and inflammation in cattle. Substance P is an undecapeptide released from the dorsal horn of the spinal cord that regulates the excitability of nociceptive neurons and is associated with the transmission and modulation of pain; furthermore, SP is involved in the integration of inflammation, stress, and anxiety (DeVane, 2001; Datar et al., 2004; Perl, 2011). Studies have used the circulating concentration of SP, among other parameters, to assess inflammation and nociception in dairy and beef calves following castration and dehorning (Coetzee et al., 2012; Allen et al., 2013; Repenning et al., 2013). Overall, circulating concentrations of SP were increased in calves following dehorning and castration, and some studies demonstrated a reduction in SP following pain management (Coetzee et al., 2012; Allen et al., 2013). However, more research is required to better understand the association of postpartum diseases such as clinical metritis and circulating concentrations of SP in lactating dairy cows.

The objectives of this study were to assess (1) daily activity patterns, and (2) circulating concentrations of $\mathrm{SP}, \mathrm{HP}$, and cortisol in lactating dairy cows diagnosed with clinical metritis. Furthermore, determination of BHB, total calcium, white blood cells, milk yield, and reproductive data were collected for a more comprehensive assessment of clinical metritis in dairy cattle. We hypothesized that cows that experience clinical metritis will have altered activity patterns, and higher circulating concentration of SP, HP, and cortisol compared with cows without clinical metritis.

\section{MATERIALS AND METHODS}

\section{Animals, Facilities, and Feeding}

During the present case-control study, lactating Holstein dairy cows $(n=200)$ that calved between August 2014 and October 2015 in 2 commercial dairy herds in South Central Ohio were enrolled. Herd A milked approximately 1,100 cows and had a yearly rolling herd average milk yield of $9,796 \mathrm{~kg}$, and herd B milked approximately 2,100 cows with a yearly rolling herd average milk yield of $10,547 \mathrm{~kg}$. Pregnant animals were allocated to prepartum freestall pens with sand bedding at approximately $21 \mathrm{~d}$ prior to their expected calving date. Pre-parturient heifers and cows displaying imminent signs of calving were moved into individual (herd A) or grouped (3-4 cows, herd B) loose straw calving pens. Following parturition, primiparous (PRIM) and multiparous (MULT) cows were comingled in a postpartum pen where they remained for approximately $21 \mathrm{~d}$. Thereafter, cows were moved to pens according to lactation number and reproductive status for the remaining of their lactation. All cows were housed in naturally ventilated 6-row freestall barns bedded with sand and had free access to feed and water. Postpartum cows (up to 21 DIM) were milked 3 and 4 times daily in herds A and B, respectively. After being moved from the postpartum pen, all cows were milked 3 times daily at approximately $8 \mathrm{~h}$ intervals in both herds. The mean stall stocking densities in the fresh pen were 89.78 and $105.29 \%$ for farm A and B, respectively. Feed was delivered once daily, and feed push up was performed at approximately 2-h intervals. Both dairy herds kept individual animal health, reproductive, and productive records using computerized record-keeping systems (Dairy Comp 305, Valley Ag Software, Tulare, CA). The procedures described below were reviewed and approved by the Institutional Animal Care Use Committee at The Ohio State University (protocol number: 2016A00000057).

\section{Animal Enrollment and Diagnosis of Clinical Metritis}

Weekly, a list of cows for diagnosis of clinical metritis was obtained using on-farm computer records based on calving dates. The cows that presented history of disease or medical treatment were excluded from the list. The vaginal discharge of lactating dairy cows was screened for diagnosis of clinical metritis using a Metricheck device (Simcro Tech Ltd., Hamilton, New Zealand) at $7 \pm 3 \mathrm{~d}$ after parturition (study d 1). Briefly, the vulva was cleaned with a paper towel and the Metricheck device was introduced through the vulva into the cranial portion of the vagina; then the 
device was gently retracted outside of the vagina. After removal, the material collected was evaluated for clinical metritis diagnosis. Clinical metritis was defined by the presence of watery, foul-smelling, reddish or brownish vaginal discharge with or without pyrexia (rectal temperature $>39.5^{\circ} \mathrm{C}$; Stangaferro et al., 2016b). Cows with clinical metritis $(\mathbf{C M} ; \mathrm{n}=100)$ were matched according to lactation and DIM to cows without clinical metritis (NO-CM; $\mathrm{n}=100$ ). A total of 61 multiparous cows and 55 first lactation cows were enrolled in farm A, whereas 63 multiparous cows and 21 first lactation cows were enrolled in farm B. On study $d 1$, animals (CM and NO-CM group) showing any signs of other disease (e.g., lameness, pneumonia, displaced abomasum, vulvovaginal lacerations) were not included in the study. Members from the study team performed the examination of the animals on study $\mathrm{d} 1$ and 7 . In addition, every day after the morning milking, the farm personnel performed examinations of the cows housed in the fresh pen following the herd veterinarian recommendations. In total, 242 animals were screened on study d 1 . However, CM $(\mathrm{n}=30)$ and NO-CM $(\mathrm{n}=12)$ cows diagnosed with any other disease (e.g., lameness, pneumonia, displaced abomasum; $\mathrm{n}=29$ ), treated for clinical metritis $(\mathrm{n}=10)$, or cows that died or were culled within $21 \pm 3$ DIM $(\mathrm{n}=3)$ were excluded from the study.

\section{Assessment of Activity Patterns}

On study d 1, following clinical metritis diagnosis, electronic data loggers (IceQube, IceRobotics, Edinburgh, UK) were placed on the hind leg on a subset of CM $(\mathrm{n}=60)$ and NO-CM $(\mathrm{n}=65)$ cows randomly selected. These electronic activity data loggers continuously recorded activity from individual cows. The activity patterns recorded included lying time (LT), number of steps (STP), number of lying bouts (LB), and lying bout duration (LBD). Activity data loggers were removed from cows on study d 7 (14 \pm 3 DIM). Activity data from individual cows was extracted via the IceReader into the IceManager (IceRobotics, Edinburgh, UK) software in 15-min time blocks. Thereafter, data were summarized and reported as daily means in an Excel spreadsheet (Microsoft Corp., Redmond, WA) for further analysis.

\section{Blood Sample Collection and Hormone Assays}

On study d 1, blood samples were collected via coccygeal blood vessels for assessment of circulating concentration of SP, HP, cortisol, total $\mathrm{Ca}, \mathrm{BHB}$, and blood cells. Blood samples for assessment of serum BHB, Ca,
HP, and cortisol concentrations were collected into 8.5-mL evacuated serum separator tubes (Vacutainer, Becton Dickinson and Co., Franklin Lakes, NJ). Blood samples for determination of plasma concentrations of SP $(3 \mathrm{~mL})$ were collected into $7 \mathrm{~mL}$ evacuated tubes with K3 EDTA (Vacutainer, Becton Dickinson and Co.). For SP sample collection, a $20 \mathrm{mM}$ solution of benzamidine hydrochloride (Sigma-Aldrich, St. Louis, MO) was prepared and $300 \mu \mathrm{L}$ were added to each K3 EDTA tube to serve as protease inhibitor as previously described (Dockweiler et al., 2013). Blood samples were stored on ice immediately after collection until processing (within $2 \mathrm{~h}$ after collection). Samples were centrifuged (15 min, 3,000 $\times \mathrm{g}$, room temperature) to harvest plasma and serum that were stored at $-20^{\circ} \mathrm{C}$ until analysis.

Serum concentrations of BHB were analyzed using the NovaVet electronic handheld device (Nova Biomedical Corporation, Waltham, MA). A BHB cut-off of $1.2 \mathrm{mmol} / \mathrm{L}$ was used to determine ketosis (Iwersen et al., 2009). Concentration of $\mathrm{Ca}$ in serum was assessed by colorimetric analysis using a commercially available kit (Calcium Liquicolor No. 0150, Stanbio Laboratory, Boerne, TX). This assay determines the quantity of Ca in biological materials by the measurement of the color intensity produced by a chemical reaction between $\mathrm{Ca}$ and ortho-cresolphthalein complexone. Cows that presented $\mathrm{Ca}$ concentrations $\leq 8.0 \mathrm{mg} / \mathrm{dL}$ were classified as hypocalcemic (Reinhardt et al., 2011). The coefficient of variation for intraassay variability was $5 \%$ and the interassay variability was $3.4 \%$. The analytical sensitivity of the assay was $2 \mathrm{ng} / \mathrm{mL}$. Plasma SP concentrations were determined by competitive radioimmunoassay technique using a double antibody system with a primary anti-cow SP (Phoenix Pharmaceuticals, Burlingame, CA) and ${ }^{125} \mathrm{I}-\mathrm{SP}$ (PerkinElmer Inc., Waltham, MA) antibody as previously described by Van Engen et al. (2014). The coefficient of variation for intraassay variability was $12.22 \%$ and the interassay variability was $14.61 \%$. The analytical sensitivity of the assay was $10 \mathrm{pg} / \mathrm{mL}$. Serum concentrations of HP were determined using a commercially available bovine HP ELISA kit (Life Diagnostics, West Chester, PA) following manufacturer's instructions. The coefficient of variation for intraassay variability was $4.83 \%$ and the interassay variability was $7.61 \%$. The analytical sensitivity of the assay was $3.91 \mathrm{ng} / \mathrm{mL}$. Furthermore, serum cortisol concentrations were assessed using a commercially available radioimmunoassay (Corti-Cote RIA kit, MP Biomedical, Irvine, CA) as previously described (Bates et al., 2014). The calculated coefficient of variation for intraassay variability was $11.03 \%$, and the interassay CV was $6.62 \%$. The analytical sensitivity of the assay was $0.625 \mathrm{pg} / \mathrm{mL}$. 
For quantification of blood cells, blood samples from a subset of cows randomly selected in the CM $(\mathrm{n}=49)$ and NO-CM $(\mathrm{n}=51)$ group were collected into $7-\mathrm{mL}$ evacuated tubes containing K3 EDTA. An aliquot of whole blood was used to assess the complete blood cell counts using the VetScan HM5 analyzer (Abaxis Inc., Union City, CA).

\section{BCS, Rectal Temperature, Milk Yield, and Fertility}

On study d 1, BCS was assessed using a 5-point scale (Ferguson et al., 1994), and rectal temperature was measured using an electronic thermometer (Cooper Atkins, Cincinnati, OH). Cows that presented rectal temperature $>39.5^{\circ} \mathrm{C}$ were classified as having pyrexia. Milk yield data from the first 3 DHIA milk tests relative to calving were collected. In addition, reproductive performance data [i.e., number of services required to conceive and DIM to conception (DIMC)] were obtained from on-farm records.

\section{Statistical Analysis}

A power calculation was run to determine the required sample size for this field trial. To be able to detect a difference in $8 \mathrm{pg}$ of SP (Repenning et al., 2013) between animals with metritis and animals without metritis, with adequate statistical power $(1-\beta=0.8)$ and significance $(\alpha=0.05)$, a sample size of 100 dairy cows per group (total of 200 animals) was required. Although the sample sizes for other biological outcomes (BHB, total $\mathrm{Ca}$, white blood cells, milk yield, and reproductive performance) assessed in the study were not computed, this information was included to further illustrate the potential negative biological responses in lactating cows experiencing metritis. The study was conducted as a prospective case-control design where cows diagnosed with clinical metritis were matched to cows without clinical metritis according to lactation number and DIM. Individual cow data (e.g., lactation number, DIM, milk yield) were extracted from computerized farm records to Microsoft Excel files. Statistical analyses were performed using SAS statistical software (version 9.4, SAS Institute Inc., Cary, NC) using cow as the experimental unit.

The normality and homogeneity of variances for the quantitative dependent variables were assessed through Shapiro-Wilk statistic, graphical methods (histogram and Q-Q plot), and Barlett's tests using the UNIVARIATE procedure of SAS. Due to lack of normality, plasma concentrations of SP, cortisol, blood cells and STP were $\log _{10}$ transformed for analysis. The results of these variables were back-transformed, and geometric means and $95 \%$ confidence intervals were reported in this study.

Continuous variables were analyzed using the MIXED procedure of SAS. For analysis of activity variables (LT, STP, LB, and LBD) and DHIA milk tests, the REPEATED statement (day) was included in the MIXED procedure. The covariate structure of each activity variable was selected based on the best fit according to Schwarz's Bayesian information criteria. The variables initially offered to the model were day, stocking density, parity, season, BCS, ketosis, hypocalcemia, DIM at test day, and CM, as well as the interaction of CM with these variables. Using the Wald statistic backward selection criterion $(P>0.15)$, the nonsignificant variables were removed. Cow within farm was included in the model as random effect. In addition, analysis of LT revealed an interaction between CM and parity; therefore, PRIM and MULT cows' data were analyzed separately. Least squares means and standard error of the mean of the continuous variables were computed and adjusted (Tukey-Kramer method) using the LSMEAN statement included in the MIXED procedure of SAS. Due to failure to achieve normality after data transformation $\left(\log _{10}, \mathrm{R}^{2}\right)$, HP and number of services required to conceive were analyzed using the nonparametric Kruskall-Wallis test through the NPAR1WAY procedure of SAS. Median and interquartile range values are reported. Binary variables (pyrexia, ketosis, and hypocalcemia) were analyzed by multivariable logistic regression using the GLIMMIX procedure of SAS. The variables initially offered to the model were stocking density, parity, season, BCS, ketosis, hypocalcemia, DIM at test day, and CM, as well as the interaction of $\mathrm{CM}$ with these variables. The Wald statistic backward selection criterion $(P>0.15)$ was also used to select the variables included in the model of each variable of interest. Cow within farm was included in the model as random effect. The variables of interest as well as their interactions were considered significant if $P<0.05$, and $P<0.10$ was considered a tendency.

\section{RESULTS}

\section{Activity Patterns}

Overall, cows in the CM group tended $(P=0.07)$ to spend more time lying $(628.92 \pm 13.65 \mathrm{~min} / \mathrm{d})$ than NO-CM cows (591.23 $\pm 17.53 \mathrm{~min} / \mathrm{d}$; Figure 1). No difference was observed in daily STP, LB, and LBD between $\mathrm{CM}$ and NO-CM cows (Figure 1). In addition, analysis by parity revealed that PRIM cows with clinical metritis spent more $(P=0.02)$ time lying $(\mathrm{CM}$ 
$=605.16 \pm 16.93 \mathrm{~min} / \mathrm{d}$ ) when compared with PRIM cows without clinical metritis $(\mathrm{NO}-\mathrm{CM}=551.01 \pm$ $16.56 \mathrm{~min} / \mathrm{d}$; Figure 2). However, there was no difference $(P=0.86)$ on daily LT between MULT cows with and without clinical metritis (Figure 2).

\section{Biomarkers of Pain, Inflammation, and Stress}

Circulating concentration of SP was higher $(P=$ $0.001)$ in CM cows $(47.15 \pm 5.38 \mathrm{pg} / \mathrm{mL})$ when compared with NO-CM cows $(37.73 \pm 5.41 \mathrm{pg} / \mathrm{mL}$; Figure $3)$. Serum circulating concentrations of HP were higher $(P<0.001)$ in cows with clinical metritis $(233.00 \pm$ $20.30 \mu \mathrm{g} / \mathrm{mL}$ ) when compared with cows without clinical metritis (99.98 $\pm 13.79 \mu \mathrm{g} / \mathrm{mL}$; Figure 4). However, no difference was observed in circulating concentration of cortisol between CM $(9.05 \pm 1.39)$ and NO-CM cows $(8.32 \pm 1.26$; Figure 5).

\section{BCS, Pyrexia, Milk Production, and Fertility}

The distribution of DIM, lactation number, average BCS, proportion of cows with pyrexia in the CM group, average milk yield, and reproductive parameters between treatment groups is presented in Table 1. Cows with clinical metritis had lower BCS compared with cows without clinical metritis (Table 1). No differences were present in milk yield in the first 3 DHIA milk tests between CM and NO-CM cows (Table 1). Furthermore, the number of services required to conceive was higher $(P<0.001)$ in the $\mathrm{CM}$ group (median of 2 services; interquartile range of 1-4 services) compared with cows in the NO-CM group (median of 2 services; interquartile range of 1-3 services). Consequently, cows with clinical metritis had increased $(P=0.02)$ DIMC $(121.25 \pm 1.10 \mathrm{~d})$ compared with cows without clinical metritis $(104.11 \pm 1.10 \mathrm{~d}$; Table 1$)$.

\section{Hormones and Blood Cells}

Serum concentration of BHB were not different between cows with $(0.87 \pm 1.09 \mathrm{mmol} / \mathrm{L})$ and without clinical metritis $(0.90 \pm 1.11 \mathrm{mmol} / \mathrm{L}$; Table 2$)$. Similarly, no difference $(P>0.05)$ in the proportion of cows with ketosis was observed between groups (Table 2). Overall, circulating concentration of Ca was lower $(P=$ $0.009)$ in cows diagnosed with clinical metritis $(8.54 \pm$ $0.26 \mathrm{mg} / \mathrm{dL})$ when compared with NO-CM cows $(8.87$ $\pm 0.27 \mathrm{mg} / \mathrm{dL}$, Table 2$)$. Furthermore, a greater $(P=$ $0.003)$ proportion of cows in the CM group had hypocalcemia compared with NO-CM cows (Table 2).

Total white blood cells were decreased $(P<0.001)$ in cows with clinical metritis $\left(7.62 \pm 0.91\right.$ cells $\left.\times 10^{6} / \mathrm{mL}\right)$ compared with cows without clinical metritis (10.46 \pm
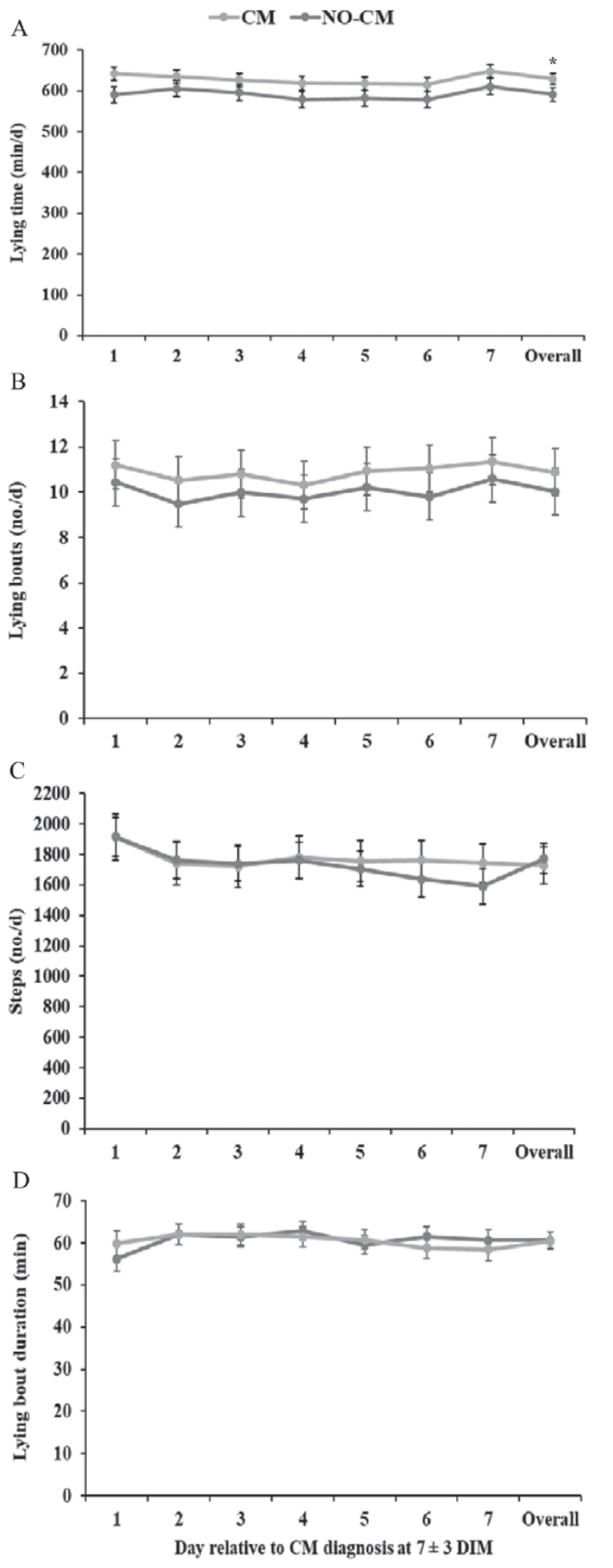

Figure 1. Daily lying time (A; min/d), number of lying bouts (B; no./d), number of steps (C; no./d), and lying bout duration (D; min) during study d 1 (diagnostic of clinical metritis; $7 \pm 3$ DIM) until study d 7 (14 \pm 3 DIM) of cows with clinical metritis $(\mathrm{CM} ; \mathrm{n}=60)$ and without clinical metritis (NO-CM; $\mathrm{n}=65$ ). Values are presented as $\mathrm{LSM} \pm \mathrm{SEM}$, except for the number of steps, which are reported as back-transformed geometric means and $95 \%$ CI. ${ }^{*} P<0.05$. 


\section{PRIM}
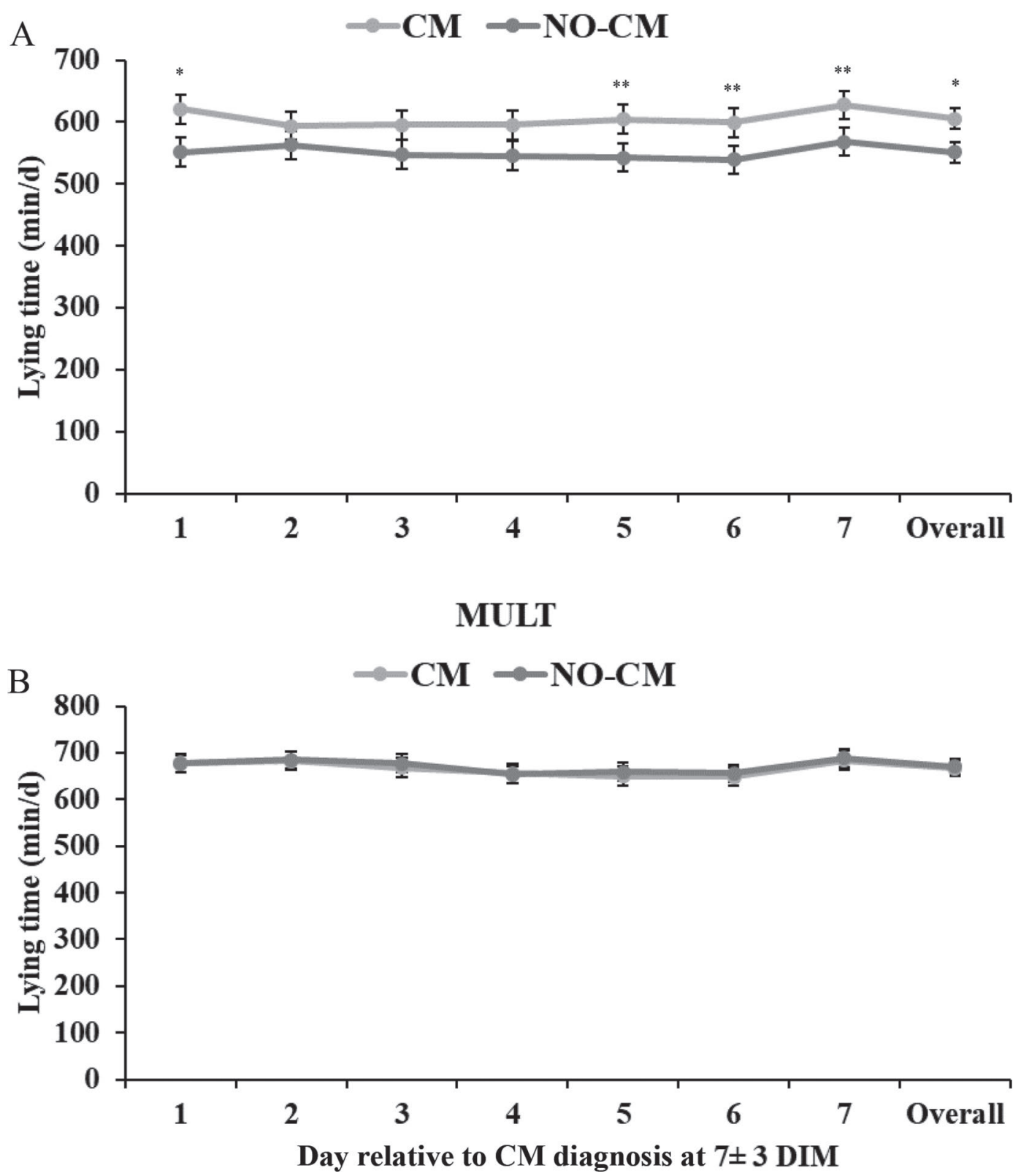

Figure 2. Daily lying time of primiparous (PRIM; A; min/d), and multiparous (MULT; B; min/d) cows with clinical metritis (CM; PRIM $=21$ and MULT = 39) and without clinical metritis (NO-CM; PRIM = 22 and MULT = 43), during study d 1 (diagnostic of clinical metritis; $7 \pm 3$ DIM) until study d 7 (14 \pm 3 DIM). Values are presented as LSM \pm SEM. ${ }^{* *} P<0.1 ; * P<0.05$.

1.19 cells $\times 10^{6} / \mathrm{mL}$; Table 3$)$. Accordingly, circulating concentration of lymphocytes, monocytes, and neutrophils were decreased in cows with clinical metritis compared with cows without clinical metritis (Table $3)$. Furthermore, circulating concentration of red blood cells was also lower $(P=0.04)$ in the $\mathrm{CM}$ group $(6.85 \pm$ 0.10 cells $\left.\times 10^{6} / \mu \mathrm{L}\right)$ cows compared with the NO-CM group $\left(7.12 \pm 0.09\right.$ cells $\times 10^{6} / \mu \mathrm{L}$; Table 3$)$.

\section{DISCUSSION}

The present study was designed to assess whether clinical metritis affected the circulating concentrations of SP, HP, and cortisol; and daily activity patterns (LT, STP, LB, and LBD) in lactating dairy cows. Results from this study showed that cows diagnosed with clinical metritis had increased circulating concentrations of 


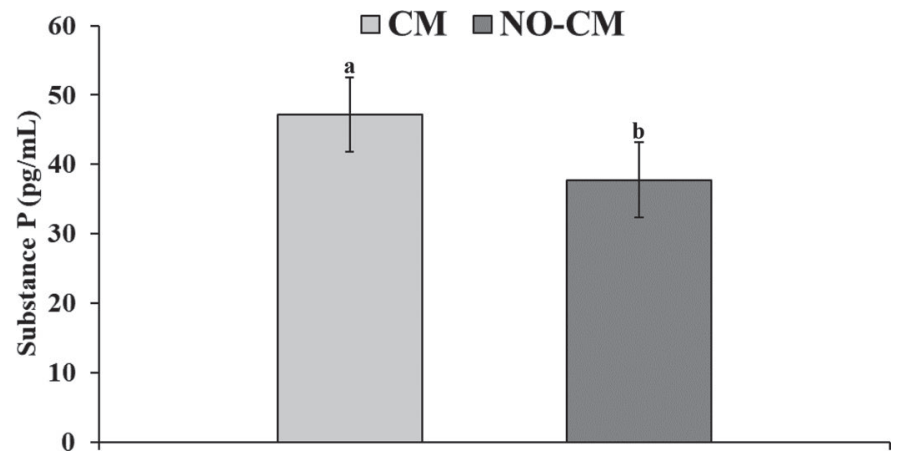

Figure 3. Circulating concentration (geometric means $\pm 95 \%$ CI) of substance $\mathrm{P}(\mathrm{pg} / \mathrm{mL})$ of cow with clinical metritis $(\mathrm{CM} ; \mathrm{n}=99)$ and without clinical metritis (NO-CM; $\mathrm{n}=95) .{ }^{\mathrm{a}, \mathrm{b}}$ Different letters indicate statistical significance at $P<0.05$

$\mathrm{SP}$ and $\mathrm{HP}$ and tended to spend more time lying than NO-CM cows. Interestingly, LT in PRIM cows diagnosed with clinical metritis was significantly increased compared with NO-CM PRIM cows, whereas activity patterns were not affected in MULT cows diagnosed with clinical metritis.

Overall, cows in the CM group tended to spend more time lying than NO-CM cows. Clinical metritis can cause systemic signs associated with sickness, such as depression and decreased appetite in dairy cows (Sheldon et al., 2006), which may explain the tendency to spend more time lying in cows with clinical metritis. Huzzey et al. (2007) reported that cows that developed clinical metritis in the early postpartum period spent less time feeding in the late prepartum period compared with cows that did not developed clinical me-

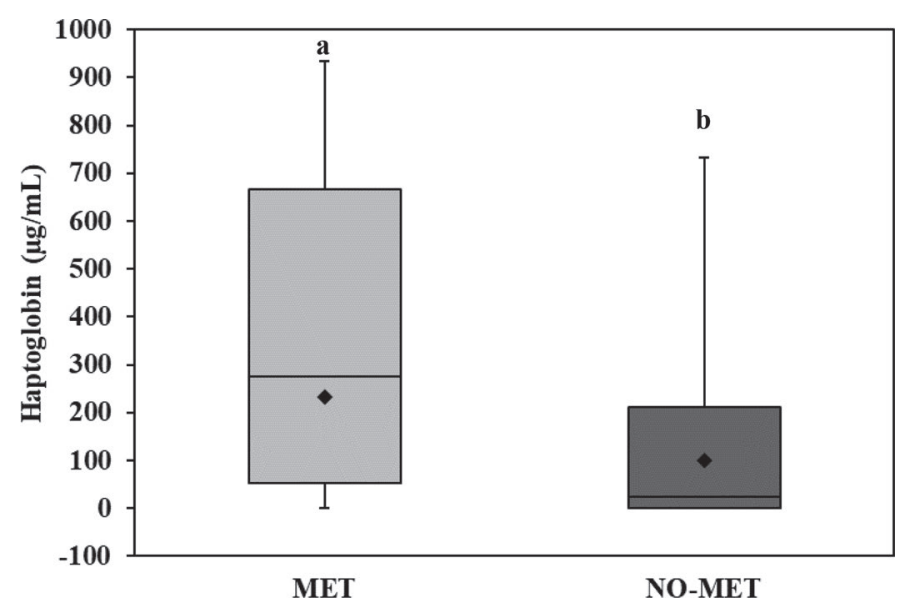

Figure 4. Serum concentration of haptoglobin $(\mu \mathrm{g} / \mathrm{mL})$ in cows with clinical metritis $(\mathrm{CM} ; \mathrm{n}=95)$ and without clinical metritis (NO$\mathrm{CM} ; \mathrm{n}=93$ ). Box plots depict 10th percentile, 25th percentile, median (solid line), 75th percentile, and 95th percentile. Solid diamonds represent the mean. ${ }^{\mathrm{a}, \mathrm{b}}$ Different letters indicate statistical significance at $P<0.05$.

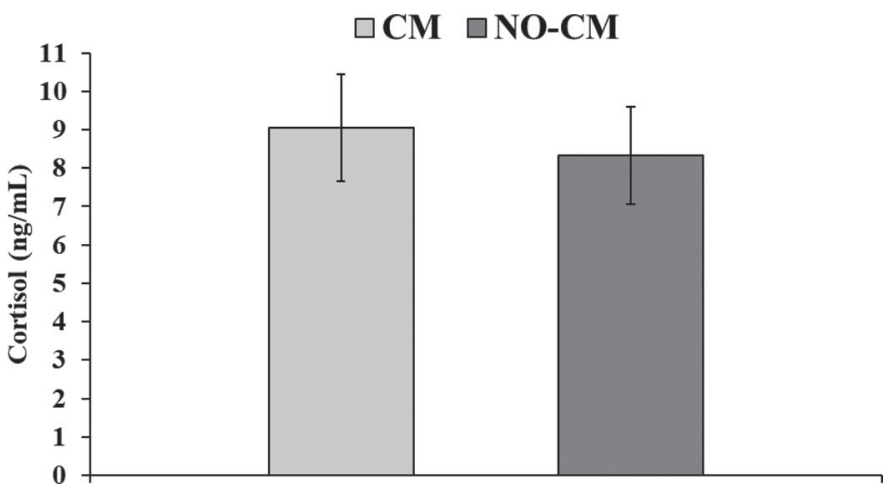

Figure 5. Circulating concentration (geometric means $\pm 95 \% \mathrm{CI})$ of cortisol $(\mathrm{ng} / \mathrm{mL})$ of cows with clinical metritis $(\mathrm{CM} ; \mathrm{n}=97)$ and without clinical metritis (NO-CM; $\mathrm{n}=99$ ).

tritis. This result agrees in part with the findings of our study, where CM cows tended to be less active. Other diseases, such as lameness and mastitis, can affect the activity patterns of dairy cows. For instance, cows with clinical mastitis induced by Escherichia coli endotoxin stood more and avoided lying on the side of the affected quarter (Siivonen et al., 2011). This reduction in LT contrasts with the typical behavior observed in sick animals, and the authors concluded that cows stood more to minimize the discomfort hat cows may experience when they lie down. de Boyer des Roches et al. (2017) reported that LT was not affected in cows with induced clinical mastitis, but they observed increased postural changes from lying to standing position compared with cows without mastitis. Thus, behavioral changes can

Table 1. Distribution of lactation number, DIM, BCS, proportion (\%) of cows with pyrexia, milk yield $(\mathrm{kg} / \mathrm{d})$ in the first 3 DHIA milk tests, and days in milk to conception (DIMC), in lactating dairy cows diagnosed with and without clinical metritis

\begin{tabular}{lrrr}
\hline & \multicolumn{2}{c}{ Clinical metritis } & \\
\cline { 2 - 3 } & \multicolumn{1}{c}{ Yes } & \multicolumn{1}{c}{ No } \\
$(\mathrm{n}=100)$ & $(\mathrm{n}=100)$ & P-value \\
Variable $^{1}$ & $2.16 \pm 0.11$ & $2.16 \pm 0.11$ & - \\
\hline Lactation number $_{\text {DIM }}$ & $7.08 \pm 0.20$ & $7.08 \pm 0.20$ & - \\
BCS & $3.06 \pm 0.05$ & $3.19 \pm 0.05$ & 0.01 \\
Pyrexia $^{3}(\%)$ & $20 \pm 4.10$ & - & - \\
DHIA test $1^{4}(\mathrm{~kg} / \mathrm{d})$ & $32.28 \pm 1.09$ & $33.53 \pm 1.09$ & 0.23 \\
DHIA test $2^{4}(\mathrm{~kg} / \mathrm{d})$ & $35.33 \pm 1.54$ & $35.62 \pm 1.54$ & 0.78 \\
DHIA test $3^{4}(\mathrm{~kg} / \mathrm{d})$ & $40.22 \pm 4.26$ & $40.58 \pm 4.26$ & 0.73 \\
DIMC & $121.25 \pm 1.10$ & $104.11 \pm 1.10$ & 0.02 \\
\hline
\end{tabular}

${ }^{1}$ Balanced for in the study design. Cows diagnosed with clinical metritis were matched according to lactation and DIM to cows without clinical metritis. Arithmetic means $\pm \mathrm{SD}$ are presented for lactation number, DIM, pyrexia, and TBRD. Least squares means \pm SEM are presented for BCS, DHIA tests, and DIMC.

${ }^{2}$ BCS was scored using a 5-point scale (Ferguson et al., 1994).

${ }^{3}$ Pyrexia was defined as rectal temperature $>39.5^{\circ} \mathrm{C}$.

${ }^{4}$ Milk yield was recorded for the first 3 DHIA tests relative to calving. 
Table 2. Circulating concentration (LSM \pm SEM) of BHB and Ca, and proportion of cows with ketosis and hypocalcemia in cows diagnosed with clinical metritis compared with cows without clinical metritis

\begin{tabular}{|c|c|c|c|}
\hline \multirow[b]{2}{*}{ Variable } & \multicolumn{2}{|c|}{ Clinical metritis } & \multirow[b]{2}{*}{$P$-value } \\
\hline & $\begin{array}{c}\text { Yes } \\
(\mathrm{n}=100)\end{array}$ & $\begin{array}{c}\text { No } \\
(\mathrm{n}=100)\end{array}$ & \\
\hline Blood BHB concentrations $(\mathrm{mmol} / \mathrm{L})$ & $0.87 \pm 1.09$ & $0.90 \pm 1.11$ & 0.72 \\
\hline $\operatorname{Ketosis}^{1}(\%)$ & $27.50 \pm 7.10$ & $23.42 \pm 7.93$ & 0.59 \\
\hline Blood Ca concentrations (mg/dL) & $8.54 \pm 0.26$ & $8.88 \pm 0.27$ & 0.009 \\
\hline Hypocalcemia $^{2}(\%)$ & $22.78 \pm 4.76$ & $1.33 \pm 1.32$ & 0.003 \\
\hline
\end{tabular}

differ in cows diagnosed with mastitis. It has been reported that lame cows had longer lying times, walked less, spent less time feeding, and visited the grooming brushes less frequently compared with nonlame cows (Whay and Shearer, 2017; Weigele et al., 2018). Injuries of the hooves or extremities directly affect the locomotor system of cows causing visible changes in gait patterns even in moderately lame cows. Thus, automated systems for detection of lactating dairy cows experiencing health disorders such as clinical metritis and mastitis are useful, but more research is needed to improve their ability to identify sick cows.

Interestingly, results of this study showed an association between clinical metritis and daily lying time in PRIM cows, but not in MULT cows. In the present study, PRIM cows with clinical metritis spent more time lying compared with cows without clinical metritis. Some authors (Humblet et al., 2006) reported that PRIM cows may experience an exacerbated inflammatory response (i.e., increased HP and amyloid A) compared with MULT cows during the early postpartum period regardless health status. This suggests that the immune system of PRIM cows may be more reactive to inflammatory stimuli. In PRIM cows this may lead to an increase in circulating cytokines, which can lead

Table 3. Total and differential white blood cell counts, and erythrocytes in cows with clinical metritis compared with cows without clinical metritis

\begin{tabular}{|c|c|c|c|}
\hline \multirow[b]{2}{*}{ Variable $^{1}$} & \multicolumn{2}{|c|}{ Clinical metritis } & \multirow[b]{2}{*}{$P$-value } \\
\hline & $\begin{array}{c}\text { Yes } \\
(\mathrm{n}=49)\end{array}$ & $\begin{array}{c}\text { No } \\
(\mathrm{n}=51)\end{array}$ & \\
\hline Total white blood cells ${ }^{2}$ & $7.62 \pm 0.91$ & $10.46 \pm 1.19$ & $<0.001$ \\
\hline Lymphocytes $^{2}$ & $4.13 \pm 0.58$ & $5.95 \pm 0.83$ & $<0.001$ \\
\hline Monocytes $^{2}$ & $0.10 \pm 0.02$ & $0.18 \pm 0.06$ & 0.001 \\
\hline Neutrophils ${ }^{2}$ & $2.65 \pm 0.36$ & $3.29 \pm 0.44$ & 0.03 \\
\hline Erythrocytes $^{3}$ & $6.85 \pm 0.10$ & $7.12 \pm 0.09$ & 0.04 \\
\hline
\end{tabular}

${ }^{1}$ Geometric means $\pm 95 \%$ CI are presented.

${ }^{2}$ Cell type $\times 10^{6} / \mathrm{mL}$.

${ }^{3}$ Cell type $\times 10^{6} / \mu \mathrm{L}$. to expression of sickness behavior (such as depression), which may help explain, at least in part, the increased LT and reduced ST that PRIM cows with clinical metritis experienced in our study.

It was recently reported that cows with clinical metritis showed physical signs of pain such as back arching at rectal examination compared with cows without clinical metritis, suggesting that clinical metritis may be associated with visceral pain (Stojkov et al., 2015). Findings from the present study showed increased SP concentration in cows diagnosed with clinical metritis compared with cows without clinical metritis. Circulating concentration of SP, among other parameters, have been used to assess nociception and inflammation in dairy and beef calves following surgical procedures such as castration and dehorning (Coetzee et al., 2008; Allen et al., 2013; Repenning et al., 2013). Overall, circulating concentrations of SP were increased in calves following dehorning and castration, and some studies were able to demonstrate a reduction in SP circulating concentrations following administration of nonsteroidal anti-inflammatory drugs (Coetzee et al., 2012; Allen et al., 2013). Similarly, SP was elevated after oligofructose-induced lameness in dairy heifers (Bustamante et al., 2015). Thus, SP has been proposed as marker associated with nociception in cattle (Coetzee et al., 2008). The elevated SP concentrations observed in cows diagnosed with clinical metritis in the present study agree with previous findings showing increased $\mathrm{SP}$ in response to nociceptive stimuli, and suggest that clinical metritis may be associated with nociception. However, SP was also elevated in beef calves following transportation, suggesting that elevated SP may also be associated with stress and anxiety (Van Engen et al., 2014). Thus, further studies are needed to elucidate if SP is a reliable indicator of pain in cows or if it is released in response to a variety of stimuli in cattle. The combination of clinical signs, behaviors, biomarkers of stress and inflammation, and the use of analgesia needs to be considered to further evaluate the association of $\mathrm{SP}$ with nociception in cows with clinical metritis. 
Haptoglobin is an acute phase protein synthesized by hepatocytes in response to cytokines released by macrophages after an inflammatory response (Cray, 2012). The release of these liver acute phase proteins can be stimulated by a wide variety of stimuli such as bacterial products and tissue damage (Cray, 2012). In the present study, the concentration of HP was increased in cows with clinical metritis compared with cows without clinical metritis, suggesting that these cows experienced a systemic inflammatory response. Elevated HP concentrations in postpartum dairy cows have been associated with infectious diseases such as clinical metritis and mastitis, and poor reproductive performance (Groonlund et al., 2005; Dubuc et al., 2010; Huzzey et al., 2015). Furthermore, elevated concentration of HP in the early postpartum period have been proposed as a predictor of clinical metritis. Huzzey et al. (2009) showed that cows with increased HP circulating concentration $(>1 \mathrm{~g} / \mathrm{L})$ at 3 DIM were 6.7 times more likely to develop clinical metritis. However, the greatest limitation of using HP as a predictor of clinical metritis is its implementation under field conditions in commercial dairy farms. Similarly, other studies found a positive association between clinical metritis and HP (Drillich et al., 2007; Chan et al., 2010; Pohl et al., 2015).

Cortisol concentration has been extensively used as parameter to measure stress associated with pain and discomfort in cattle (Coetzee, 2011). Comin et al. (2013) reported higher hair cortisol concentrations in cows with clinical metritis compared with healthy cows. However, hair cortisol reflects the production of cortisol for weeks or even months before sample collection (Comin et al., 2013), whereas in our study serum cortisol was measured, which has been associated with an acute stress and pain response (Coetzee, 2011). Furthermore, Comin et al. (2013) did not account for the days from calving when comparing cows with clinical metritis and healthy animals, and it has been reported that DIM affects the concentration of hair cortisol (Burnett et al., 2015). In contrast, Kaczmarowski et al. (2006) reported no differences between cows with and without clinical metritis in serum concentration of cortisol, which agreed with the results reported in our study. Because plasma cortisol can be confounded by the stress associated with handling, restraining, and sampling, we may have failed to observe differences in plasma cortisol concentrations in the present study. Substance P, HP, and cortisol are released in response to various stimuli. Thus, elevated circulating concentrations of these biomarkers can be observed in cows suffering from various health disorders. For this reason, to minimize the confounding effects associated with SP, HP, and cortisol, all animals treated for health disorders other than clinical metritis, or animals that were culled or died within $21 \mathrm{~d}$ after parturition were excluded from CM and NO-CM groups.

The total concentration of circulating WBC was decreased in cows with clinical metritis compared with cows without clinical metritis. Furthermore, differential WBC analysis revealed that all cell types were decreased in CM cows compared with NO-CM cows. Decreased WBC can be caused by bacterial and viral infections such as clinical metritis, mastitis, and pneumonia (Jones and Allison, 2007). However, in subacute or chronic cases of clinical metritis, neutrophils can be increased in peripheral blood (Divers and Peek, 2007). The decreased concentration of WBC in peripheral blood in cows with clinical metritis observed in this study could be explained by the circulating leukocytes influx toward the uterine lumen. Additionally, erythrocytes were decreased in cows with clinical metritis compared with cows without clinical metritis. In cows that experience clinical metritis, the layers of the uterus are compromised (Divers and Peek, 2007), which could produce the rupture of the uterine submucosa blood vessels causing internal hemorrhage. This might explain, at least in part, the decreased concentration of erythrocytes in the CM cows observed in this study.

Milk yield in the first 3 DHIA tests relative to calving was not different between $\mathrm{CM}$ and NO-CM cows in the present study. These findings disagree with some literature published (Deluyker et al., 1991; Rajala and Gröhn, 1998) and agrees with others (Dohoo and Martin, 1984; Lucey et al., 1986). A more dramatic reduction in milk production may be observed in cows that experience clinical metritis associated with systemic clinical signs. In the present study, approximately $20 \%$ of the cows with clinical metritis were classified as having pyrexia at 4 to 10 DIM; however, because the first DHIA test was performed on average at 26 DIM (data not shown), we may have failed to observe this effect. The DIMC were greater in the CM group, and cows with clinical metritis required more services to become pregnant compared with NO-CM cows, which agrees with previous studies (Fourichon et al., 2000). Furthermore, the BCS of cows with clinical metritis was lower compared with cows without clinical metritis. Huzzey et al. (2007) reported that cows that developed clinical metritis spent less time feeding and consumed less feed in the late prepartum period compared with cows that did not develop clinical metritis. This may explain, at least in part, the findings regarding BCS presented in this study. Maintaining an optimal DMI and BCS during the early postpartum period is crucial to avoid metabolic diseases such as ketosis and hypocalcemia in dairy cows (LeBlanc, 2010). In our study, a greater proportion of cows with CM had hypocalcemia. Meta- 
bolic diseases such as hypocalcemia impair the immune system function in dairy cows, increasing the risk of developing infectious diseases such as CM in early lactation (Ingvartsen and Moyes, 2013; Martinez et al., 2014).

\section{CONCLUSIONS}

Cows with clinical metritis had increased LT and elevated circulating concentration of SP and HP, compared with cows without clinical metritis. Interestingly, based on activity data PRIM cows with clinical metritis appear to be more severely affected, since PRIM cows diagnosed with clinical metritis spent more time lying compared with NO-CM PRIM cows, whereas no difference in LT was observed in MULT cows. Overall, results showed increased concentrations of markers of inflammation, stress, and pain, and altered activity in cows with clinical metritis; thus, strategies aimed to minimize the negative effects associated with clinical metritis may be required to improve the welfare of dairy cows.

\section{ACKNOWLEDGMENTS}

The authors thank farm owners and personnel from the dairy operations that participated in this study for the help provided to the research team and allowing the use of their animals and facilities to perform this project. Special thanks to J. F. Coetzee and the Veterinary Diagnostic Lab (PhAST) at Iowa State University for the assistance provided with SP and cortisol laboratory analysis. In addition, authors thank undergraduate and graduate students that helped with sample collection. We also acknowledge the Ohio Dairy Producers Association (Columbus) for providing partial funding for this study.

\section{REFERENCES}

Allen, K.A., J.F. Coetzee, L.N. Edwards-Callaway, H. Glynn, J. Dockweiler, B. KuKanich, H. Lin, C. Wang, E. Fraccaro, M. Jones, and L. Bergamasco. 2013. The effect of timing of oral meloxicam administration on physiological responses in calves after cautery dehorning with local anesthesia. J. Dairy Sci. 96:5194-5205.

Bates, J. L., L. A. Karriker, M. L. Stock, K. M. Pertzborn, L. G. Baldwin, L. W. Wulf, C. J. Lee, C. Wang, and J. F. Coetzee. 2014. Impact of transmammary-delivered meloxicam on biomarkers of pain and distress in piglets after castration and tail docking. PLoS One 9:e113678.

Bondurant, R. H. 1999. Inflammation in the bovine female reproductive tract. J. Anim. Sci. 77:101-110.

Burnett, T. A., A. M. Madureira, B. F. Silper, A. Tahmasbi, A. Nadalin, D. M. Veira, and R. L. Cerri. 2015. Relationship of concentrations of cortisol in hair with health, biomarkers in blood, and reproductive status in dairy cows. J. Dairy Sci. 98:4414-44426.
Bustamante, H. A., A. R. Rodríguez, D. E. Herzberg, and M. P. Werner. 2015. Stress and pain response after oligofructose inducedlameness in dairy heifers. J. Vet. Sci. 16:405-411.

Chan, J. P.-W., C.-C. Chang, W.-L. Hsu, W.-B. Liu, and T.-H. Chen. 2010. Association of increased serum acute-phase protein concentrations with reproductive performance in dairy cows with postpartum metritis. Vet. Clin. Pathol. 39:72-78.

Coetzee, J. F. 2011. A review of pain assessment techniques and pharmacological approaches to pain relief after bovine castration: practical implications for cattle production within the United States. Appl. Anim. Behav. Sci. 135:192-213.

Coetzee, J. F., B. V. Lubbers, S. E. Toerber, R. Gehring, D. U. Thomson, B. J. White, and M. D. Apley. 2008. Plasma concentrations of substance $\mathrm{P}$ and cortisol in beef calves after castration or simulated castration. Am. J. Vet. Res. 69:751-762.

Coetzee, J. F., R. A. Mosher, B. KuKanich, R. Gehring, B. Robert, J. B. Reinbold, and B. J. White. 2012. Pharmacokinetics and effect of intravenous meloxicam in weaned Holstein calves following scoop dehorning without local anesthesia. BMC Vet. Res. 8:153.

Comin, A., T. Peric, M. Corazzin, M. C. Veronesi, T. Meloni, V. Zufferli, G. Cornacchia, and A. Prandi. 2013. Hair cortisol as a marker of hypothalamic-pituitary-adrenal axis activation in Friesian dairy cows clinically or physiologically compromised. Livest. Sci. $152: 36-41$.

Cray, C. 2012. Acute phase proteins in animals. Prog. Mol. Biol. Transl. Sci. 105:113-150.

Datar, P., S. Srivastava, E. Coutinho, and G. Govil. 2004. Substance P: Structure, function, and therapeutics. Curr. Top. Med. Chem. 4:75-103.

Deluyker, H. A., J. M. Gay, L. D. Weaver, and A. S. Azari. 1991. Change of milk yield with clinical diseases for a high producing dairy herd. J. Dairy Sci. 74:436-445.

de Boyer des Roches, A. D. B., M. Faure, A. Lussert, V. Herry, P. Rainard, D. Durand, and G. Foucras. 2017. Behavioral and pathophysiological response as possible signs of pain in dairy cows during Escherichia coli mastitis: A pilot study. J. Dairy Sci. 100:83858397.

DeVane, C. L. 2001. Substance P: A new era, a new role. Pharmacotherapy 21:1061-1069.

Divers, T. J., and S. Peek. 2007. Rebhun's Diseases of Dairy Cattle. Elsevier Health Sciences, Philadelphia, PA.

Dockweiler, J. C., J. F. Coetzee, L. N. Edwards-Callaway, N. M. Bello, H. D. Glynn, K. A. Allen, M. E. Theurer, M. L. Jones, K. A. Miller, and L. Bergamasco. 2013. Effect of castration method on neurohormonal and electroencephalographic stress indicators in Holstein calves of different ages. J. Dairy Sci. 96:4340-4354.

Dohoo, I. R., and S. W. Martin. 1984. Disease, production and culling in Holstein-Friesian cows III. Disease and production as determinants of disease. Prev. Vet. Med. 2:671-690.

Drillich, M., D. Voigt, D. Forderung, and W. Heuwieser. 2007. Treatment of acute puerperal metritis with flunixin meglumine in addition to antibiotic treatment. J. Dairy Sci. 90:3758-3763.

Dubuc, J., T. F. Duffield, K. E. Leslie, J. S. Walton, and S. J. LeBlanc. 2010. Risk factors for postpartum uterine diseases in dairy cows. J. Dairy Sci. 93:5764-5771.

Ferguson, J. D., D. T. Galligan, and N. Thomsen. 1994. Principal descriptors of body condition score in Holstein cows. J. Dairy Sci. 77:2695-2703.

Fitzpatrick, J. N. 2002. Observers perceptions of pain in cattle. Cattle Pract. 10:209-212.

Fourichon, C., H. Seegers, and X. Malher. 2000. Effect of disease on reproduction in the dairy cow: A meta-analysis. Theriogenology 53:1729-1759.

Gilbert, R. O. 2016. Management of reproductive disease in dairy cows. Vet. Clin. North Am. Food Anim. Pract. 32:387-410.

Gröhn, Y. T., P. J. Rajala-Schultz, H. G. Allore, M. A. DeLorenzo, J. A. Hertl, and D. T. Galligan. 2003. Optimizing replacement of dairy cows: Modeling the effects of diseases. Prev. Vet. Med. $61: 27-43$. 
Gronlund, U., C. H. Sandgren, and K. Persson Waller. 2005. Haptoglobin and serum amyloid A in milk from dairy cows with chronic sub-clinical mastitis. Vet. Res. 36:191-198.

Humblet, M.-F., H. Guyot, B. Boudry, F. Mbayahi, C. Hanzen, F. Rollin, and J.-M. Godeau. 2006. Relationship between haptoglobin, serum amyloid A, and clinical status in a survey of dairy herds during a 6-month period. Vet. Clin. Pathol. 35:188-193.

Huzzey, J. M., T. F. Duffield, S. J. LeBlanc, D. M. Veira, D. M. Weary, and M. A. G. von Keyserlingk. 2009. Short communication: Haptoglobin as an early indicator of metritis. J. Dairy Sci. 92:621-625.

Huzzey, J. M., S. Mann, D. V. Nydam, R. J. Grant, and T. R. Overton. 2015. Associations of peripartum markers of stress and inflammation with milk yield and reproductive performance in Holstein dairy cows. Prev. Vet. Med. 120:291-297.

Huzzey, J. M., D. V. Nydam, R. J. Grant, and T. R. Overton. 2011. Associations of prepartum plasma cortisol, haptoglobin, fecal cortisol metabolites, and nonesterified fatty acids with postpartum health status in Holstein dairy cows. J. Dairy Sci. 94:5878-5889.

Huzzey, J. M., D. M. Veira, D. M. Weary, and M. A. G. von Keyserlingk. 2007. Prepartum behavior and dry matter intake identify dairy cows at risk for metritis. J. Dairy Sci. 90:3220-3233.

Ingvartsen, K. L., and K. Moyes. 2013. Nutrition, immune function and health of dairy cattle. Animal 7:112-122.

Iwersen, M., U. Falkenberg, R. Voigtsberger, D. Forderung, and W. Heuwieser. 2009. Evaluation of an electronic cowside test to detect subclinical ketosis in dairy cows. J. Dairy Sci. 92:2618-2624.

Jones, M. L., and R. W. Allison. 2007. Evaluation of the ruminant complete blood cell count. Vet. Clin. North Am. Food Anim. Pract. 23:377-402.

Kaczmarowski, M., E. Malinowski, and H. Markiewicz. 2006. Some hormonal and biochemical blood indices in cows with retained placenta and puerperal metritis. Bull. Vet. Inst. Pulawy 50:89.

LeBlanc, S. 2010. Monitoring metabolic health of dairy cattle in the transition period. J. Reprod. Dev. 56(Suppl):S29-S35.

Liboreiro, D. N., K. S. Machado, P. R. Silva, M. M. Maturana, T. K. Nishimura, A. P. Brandão, M. I. Endres, and R. C. Chebel. 2015. Characterization of peripartum rumination and activity of cows diagnosed with metabolic and uterine diseases. J. Dairy Sci. 98:6812-6827.

Lucey, S., G. J. Rowlands, and A. M. Russell. 1986. Short-term associations between disease and milk yield of dairy cows. J. Dairy Res. 53:7-15.

Martinez, N., L. D. P. Sinedino, R. S. Bisinotto, E. S. Ribeiro, G. C. Gomes, F. S. Lima, L. F. Greco, C. A. Risco, K. N. Galvão, D. Taylor-Rodriguez, J. P. Driver, W. W. Thatcher, and J. E. P. Santos. 2014. Effect of induced subclinical hypocalcemia on physiological responses and neutrophil function in dairy cows. J. Dairy Sci. 97:874-887.
Perl, E. R. 2011. Pain mechanisms: A commentary on concepts and issues. Prog. Neurobiol. 94:20-38.

Pohl, A., O. Burfeind, and W. Heuwieser. 2015. The associations between postpartum serum haptoglobin concentration and metabolic status, calving difficulties, retained fetal membranes, and metritis. J. Dairy Sci. 98:4544-4551.

Rajala, P. J., and Y. T. Gröhn. 1998. Effects of dystocia, retained placenta, and metritis on milk yield in dairy cows. J. Dairy Sci. $81: 3172-3181$

Reinhardt, T. A., J. D. Lippolis, B. J. McCluskey, J. P. Goff, and R. L. Horst. 2011. Prevalence of subclinical hypocalcemia in dairy herds. Vet. J. 188:122-124.

Repenning, P. E., J. K. Ahola, R. J. Callan, J. T. French, R. L. Giles, B. J. Bigler, J. F. Coetzee, L. W. Wulf, R. K. Peel, J. C. Whittier, J. T. Fox, and T. E. Engle. 2013. Impact of oral meloxicam administration before and after band castration on feedlot performance and behavioral response in weanling beef bulls. J. Anim. Sci. 91:4965-4974.

Sheldon, I. M., G. S. Lewis, S. LeBlanc, and R. O. Gilbert. 2006. Defining postpartum uterine disease in cattle. Theriogenology 65:1516-1530

Siivonen, J., S. Taponen, M. Hovinen, M. Pastell, B. J. Lensink, S. Pyorala, and L. Hanninen. 2011. Impact of acute clinical mastitis on cow behaviour. Appl. Anim. Behav. Sci. 132:101-106.

Stangaferro, M. L., R. Wijma, L. S. Caixeta, M. A. Al-Abri, and J. O. Giordano. 2016a. Use of rumination and activity monitoring for the identification of dairy cows with health disorders: Part I. Metabolic and digestive disorders. J. Dairy Sci. 99:7395-7410.

Stangaferro, M. L., R. Wijma, L. S. Caixeta, M. A. Al-Abri, and J. O. Giordano. 2016b. Use of rumination and activity monitoring for the identification of dairy cows with health disorders: Part III. Metritis. J. Dairy Sci. 99:7422-7433.

Stojkov, J., M. A. G. von Keyserlingk, J. N. Marchant-Forde, and D. M. Weary. 2015. Assessment of visceral pain associated with metritis in dairy cows. J. Dairy Sci. 98:5352-5361.

Van Engen, N. K., M. L. Stock, T. Engelken, R. C. Vann, L. W. Wulf, L. A. Karriker, W. D. Busby, J. Lakritz, A. J. Carpenter, B. J. Bradford, W. H. Hsu, C. Wang, and J. F. Coetzee. 2014. Impact of oral meloxicam on circulating physiological biomarkers of stress and inflammation in beef steers after long-distance transportation. J. Anim. Sci. 92:498-510.

Weigele, H. C., L. Gygax, A. Steiner, B. Wechsler, and J. B. Burla. 2018. Moderate lameness leads to marked behavioral changes in dairy cows. J. Dairy Sci. 101:2370-2382.

Whay, H. R., and J. K. Shearer. 2017. The impact of lameness on welfare of the dairy cow. Vet. Clin. Food Anim. 33:153-164. 